\title{
The quality of medical services in a subjective assessment of hospitalized patients using the SERVQUAL method - a pilot study
}

\author{
PAWEŁ WĘGŁOWSKI'1, A, B, D-F, DANUTA ZWOLIŃSKA², A, D, F, PIOTR KARNIEJ) ${ }^{3, \text { A, D-F, }}$ \\ KAROLINA NOCUŃ-WASILEWSKA ${ }^{4, \mathbf{B}, \mathbf{D}, \mathbf{E}}$, DOROTA POLAK-JONKISZ ${ }^{2, \mathbf{A}, \mathbf{B}, \mathbf{D}-\mathbf{F}}$
}

\author{
${ }^{1}$ S7 Medical Company Sp. z o.o. \\ ${ }^{2}$ Department and Clinic of Pediatric Nephrology at the Faculty of Postgraduate Medical Training, Medical \\ University of Wroclaw \\ ${ }^{3}$ Department of Public Health at the Faculty of Health Science, Medical University of Wroclaw \\ ${ }^{4}$ Department and Clinic of Nephrology at the Faculty of Postgraduate Medical Training, Medical University \\ of Wroclaw
}
A - Study Design, B - Data Collection, C - Statistical Analysis, D - Data Interpretation, E - Manuscript Preparation, $\mathbf{F}$ - Literature Search, $\mathbf{G}$ - Funds Collection

Summary Background. The provision of medical services to patients according to their expectations and needs is necessary for the comfort and quality of life of patients, as well as for the standardization of hospital procedures. In recognizing these needs and expectations, an important step is the verification of provided services in order to improve their quality. The present study was designed to determine differences in service quality, as evaluated by hospitalized patients.

Objectives. The analysis of the subjective feelings of hospitalized patients concerning service quality in the context of the application of the SERVQUAL method - a pilot study.

Material and methods. The study was conducted in a Lower Silesian hospital in a group of 29 young patients (women: 16, men: 13, average age: 16) diagnosed with kidney disease. In the study a standard sheet of 22 SERVQUAL statements was used, and an analysis of the validity of 5 quality areas important for the patient was conducted.

Results. According to the respondents, the most important of all 5 features directly affecting the quality of life during treatment is the ability and skill of the ward staff to provide medical services, so-called reliability $-24.48 \%$. In turn, the least important of all the study characteristics was the aesthetics and ergonomics of rooms, the presence of appropriate equipment, the so-called material dimension $-15.31 \%$. Furthermore, service quality gaps were visible in all five service quality dimensions.

Conclusions. 1. The SERVQUAL method helps to identify discrepancies between the perceptions of patients' expectations in all dimensions of the quality of provided medical services. 2. For the patients the least important is the material dimension, and the most affecting is the dimension associated with the reliability of the medical services. 3. Improvement of the level of satisfaction with the quality of medical services requires proper planning and effective actions while providing health care services. 4 . It is recommended to conduct the study on a larger population of patients.

Key words: medical service, SERVQUAL, quality of medical services.

\section{Background}

The issue of patients' quality of life has constituted a subject of interest for researchers, theorists and employees in the medical sector for many years. Therefore, it is believed that the concept of "quality of life" is an interdisciplinary term, analyzed and defined from the point of view of medicine, psychology, sociology, philosophy and social economy. The term "quality of life" was first introduced in the USA $[1,2]$. The undoubted pioneers in this field were A. Campbell, F. Andrews and S. Whitney. They started the work of assessing the level of life satisfaction in American society $[1,3]$. At that time their aim was the comprehensive improvement of the quality of life, although initially only the area of material goods was considered. The following years demonstrated that the issue of the improvement of patients' quality of life also comprises the aspects of education, health, freedom and happiness.
In the context of quality of life, the conception of HealthRelated Quality of Life (HRQoL), which was formulated on the basis of the WHO health definition as "the functional effect of an illness and its consequent therapy upon a patient, as perceived by the patient", should be mentioned [1-3]. The difference between health - as objectively assessed by the patient on the basis of disease manifestations from different organs, and quality of life conditioned by health - as subjectively assessed, and able to change over time [1, 2] was indicated.

The quality of life of patients is related to broadly defined medical, occupational and psychosocial rehabilitation. Its level depends on determinants such as: age of the patient, type of disease and possibility of conducting therapy, duration of the disease, individual psychophysical conditions, and support from the environment [1, 4, 5]. Adult patients, as well as pediatric patients need professional medical support which will help them to deal with every stage of the disease, especially during hospitalization. 
With the increase in the awareness of the patient, more and more attention is being paid to the relationships between the patient and medical staff, both in out-patient and in-patient health care. Patients expect from the "white staff" modern diagnostic and therapeutic procedures and professionalism. A hospital stay for most patients is associated with a subjective reduction in quality of life, despite high standardization of medical services. In this particular case the perceived quality of life is intertwined with the quality of the health care service. Therefore, the assessment of the quality of a medical service on one hand is associated with the expectations of the patients, and on the other hand with feelings/experiences after the received service. According to Grönroosa, the quality of the received health care services has two dimensions: technical quality and functional quality [6]. The technical quality of health care services is the basis for identifying the authenticity of procedures and management. At the same time, functional quality is associated with preclinical aspects [7]. In order to ensure that medical procedures are effective not only from the point of view of an expert (technical quality), but also have the ability to comply with functional quality according to the patients, these expectations must be considered based on the access to health care systems. Therefore, it is important to assess the services directly and indirectly from the point of view of the patient [7]. The provision of services in line with the needs and expectations of the patient is essential for the development of the medical industry in the competitive environment which the health care market undoubtedly is [8].

There are different methods to determine the expectations of patients, but the SERVQUAL method is one of the best and most commonly used. This method is mainly used to investigate the relationship between service - from an economic point of view and the customer. In the available literature few reports presenting the use of the SERVQUAL method in the evaluation of hospital services, which may also affect the quality of life of patients, were found.

This tool, used mainly to measure the quality of service, has five dimensions and 22 items to measure the expectations and perceptions of patients [9]. SERVQUAL accurately assesses satisfaction and impact on the perception of quality by patients related to services they receive and compares them with ideal expectations. Parasurman believes that the quality of services is associated with their expectations before and after delivery of a medical service. He also indicates the gap of services as the difference between a customer's expectations and their perception. This model is also considered a model of an analyzer of the space between the gaps, and is the most powerful tool in assessing the quality of services (according to [10]).

\section{Objectives}

The aim of the study is to analyze subjective assessment of medical service quality made by hospitalized patients in the context of the application of the SERVQUAL method.

\section{Material and methods}

The survey study was performed in one of the Lower Silesian hospitals from December 2015 to March 2016. To conduct the survey it was required to obtain the oral consent of the parents or legal guardians of the patients.

The study population comprised 29 people: women (F): $16(55.1 \%)$, men $(\mathrm{M}): 13(44.9 \%)$. In the study group 9 patients $(31.03 \%)$ were 15 years old (F: 7, M: 2), 8 patients $(27.59 \%)$ were 16 years old (F: 4, M: 4), while 12 patients $(41.38 \%)$ reported the age of 17 in the survey questionnaire
(F: 5, M: 7). The selection of the group was purposive - it included children over 15 years of age, able to co-decide, staying in the hospital for not less than two days (with another hospital stay confirmed). The survey with questions was each time discussed with respondents by an experienced interviewer before its completion. The PAPI method was used, and formulated questions were clear for the respondents. The reason for the hospitalization of the surveyed patients was the need for procedures related to the diagnosis or treatment of diseases of the urinary tract. During the stay in hospital, in the study population a total of 27 patients (93.1\%) actively undertook school activity, while only 2 patients $(6.9 \%)$ did not undertake the above-mentioned activity. The respondents rated their economic and financial situation as good - 20 subjects $(68.97 \%), 7$ patients $(24.14 \%)$ estimated it as average, 1 patient $(3.45 \%)$ as bad, and 1 patient as very good $(3.45 \%)$. The respondents were also asked about their place of residence. The highest number of hospitalized subjects lived in a village - 12 patients $(41.38 \%)$, in towns up to 10 thousand inhabitants -6 patients $(20.69 \%)$, up to 100 thousand inhabitants -7 patients $(24.14 \%)$ and in cities of over 100 thousand - 4 patients of the hospital (13.79\%).

The measurement of the characteristics of the respondents such as age, sex, place of residence, financial status and school activity is presented in Table 1.

For the purpose of the authors' own research, a basic version of the SERVQUAL survey questionnaire, which allows for demonstrating differences between the quality expected and experienced by the patient within specific elements of a service/benefit, was used.

The questionnaire contained 22 questions concerning various spheres of life, divided into 5 categories:

1. Material dimension - external and internal appearance of the hospital, cleanliness, appearance of staff, quality of means, presence of medical equipment and devices, media (information about the facility, marking) - 5 statements.

2. Reliability - ability to provide services compliant with the offer, accuracy, correctness of procedures -5 statements.

3. Readiness - readiness to meet patients' expectations, willingness to provide assistance to patients and their guardians, efficiency during admission to hospital, quality and reliability of information about treatment plans -4 statements.

4. Competence and trust - competence and trust, presenting extensive knowledge and professional skills, politeness and ability of the staff to create an atmosphere of trust and confidence, respect for patients' privacy -3 statements.

5. Empathy - individual approach to the patient, understood as giving attention to each patient, ability to identify patients' needs, ability to empathize with the situation of the patient, satisfying his/her needs for contact with the outside world - 5 statements.

In the SERVQUAL method the results of the study are calculated based on the mean evaluation for each question. Then, the evaluation for the expected quality and experienced quality for a given dimension are compared. Therefore, three situations may take place:

1) expected value $=$ experienced value,

2) expected value $>$ experienced value,

3) expected value $<$ experienced value.

In the survey a five-point Likert scale was used, wherein digit 1 (in the case of the assessment of the patient's expectation) means that a given factor is insignificant, while 5 means that this factor is very significant. In the case of the assessment of the quality of a received service, digit 1 meant a very low assessment of a given factor, while 5 means a very high assessment. Subsequently, according to the SERVQUAL model, a technique of dividing a total of 100 points by the respondents between 5 dimensions of quality, in order to determine their importance (significance, impact on the perception of the quality of life) for the patients, was 


\begin{tabular}{|c|c|c|c|c|c|c|c|}
\hline \multicolumn{2}{|c|}{ Characteristics of the study patients } & \multicolumn{2}{|c|}{ Women } & \multicolumn{2}{|c|}{ Men } & \multicolumn{2}{|c|}{ Research sample } \\
\hline & & \multirow{2}{*}{$\frac{n}{16}$} & \multirow{2}{*}{$\begin{array}{l}\% \\
55.1 \\
\end{array}$} & \multirow{3}{*}{\begin{tabular}{|l|}
$n$ \\
13 \\
7 \\
\end{tabular}} & \multirow{2}{*}{$\begin{array}{l}\% \\
44.9 \\
\end{array}$} & \multirow{2}{*}{$\frac{n}{29}$} & \multirow{2}{*}{$\begin{array}{l}\% \\
100 \\
\end{array}$} \\
\hline & & & & & & & \\
\hline \multirow[t]{3}{*}{ Age } & 17 years old & 5 & 31.25 & & 53.85 & 12 & 41.38 \\
\hline & 16 years old & 4 & 25 & 4 & 30.77 & 8 & 27.59 \\
\hline & 15 years old & 7 & 43.75 & 2 & 15.38 & 9 & 31.03 \\
\hline \multirow[t]{4}{*}{ Place of residence } & village & 3 & 18.75 & 9 & 69.24 & 12 & 41.38 \\
\hline & town up to 10 thousand & 4 & 25 & 2 & 15.38 & 6 & 20.69 \\
\hline & town up to 100 thousand & 6 & 37.5 & 1 & 7.69 & 7 & 24.14 \\
\hline & city over 100 thousand & 3 & 18.75 & 1 & 7.69 & 4 & 13.79 \\
\hline \multirow[t]{4}{*}{ Economic situation } & very good & 0 & 0 & 1 & 7.69 & 1 & 3.45 \\
\hline & good & 13 & 81.25 & 7 & 53.85 & 20 & 68.97 \\
\hline & average & 3 & 18.75 & 4 & 30.77 & 7 & 24.14 \\
\hline & bad & 0 & 0 & 1 & 7.69 & 1 & 3.45 \\
\hline \multirow[t]{2}{*}{ School activity } & yes & 14 & 87.5 & 13 & 100 & 27 & 93.10 \\
\hline & no & 2 & 12.5 & 0 & 0 & 2 & 6.90 \\
\hline
\end{tabular}

Source: authors' own elaboration. $n$ - number of respondents.

used. The respondents first assessed their expectations from the hospital stay, and then evaluated the benefits and services received in the same facility.

\section{Results}

As shown in Figure 1, the respondents assessed the level of expected quality and the level of quality provided to them in a medical service. Based on the study, the average score of expectation was high -97.64 points. Among the five dimensions of quality (five-point Likert scale 1-5) the respondents demonstrated the highest expectations for the dimension "readiness" (98.8 points). The lowest expectations were related to the dimension "empathy" (97.2 points).
Furthermore, the participants of the study indicated dimensions which, according to them, most affect the quality in the context of a provided medical service. According to the respondents, the dimension which, in their opinion, most affected the quality of life by the provided service was the dimension of "reliability" (87 points), while the least affecting dimension was "material dimension", with a score of 61.3 points.

In turn, in Figure 2, the dimension of quality in the assessment of the surveyed patients in presented.

In this assessment the respondents indicated the greatest significance for the dimension "reliability" (24.48\%), followed by "professionalism and trust", "readiness", "empathy". In last position the respondents placed the "material dimension" (15.31\%) as the least affecting.

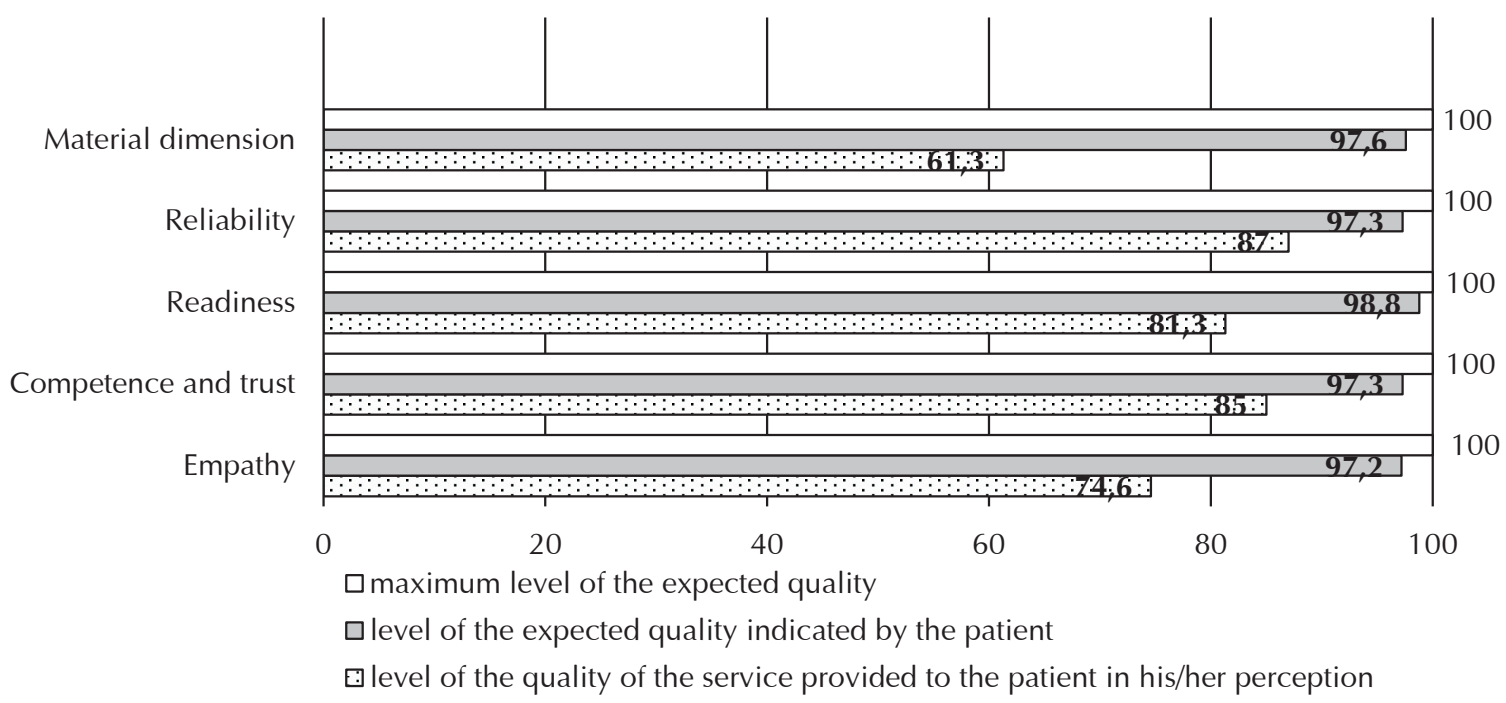

Figure 1. Assessment of the significance of the dimensions of quality, including the difference between the values expected and experienced by the patient.

Source: authors' own elaboration. 


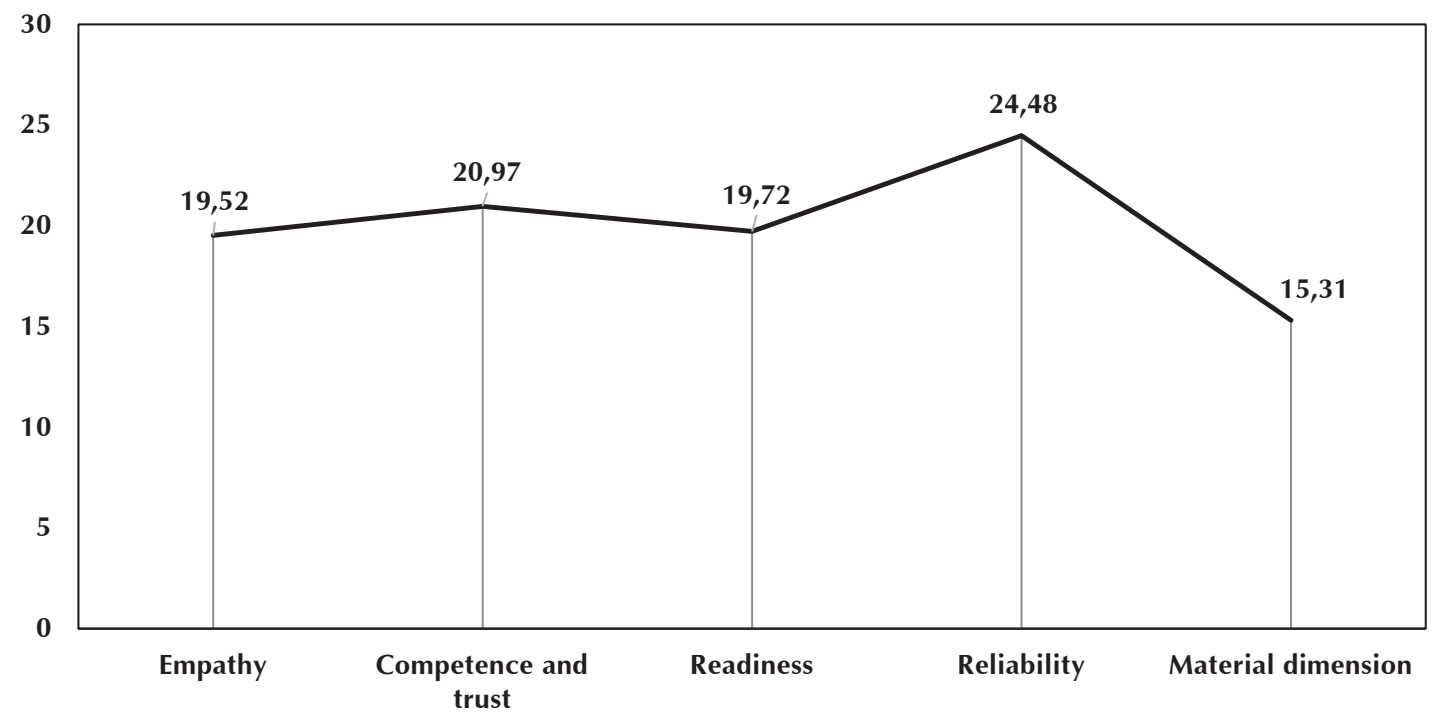

Figure 2. The significance of the dimensions of quality for the patient

Source: authors' own elaboration.

\section{Discussion}

Every medical facility providing services both on out-patient and in-patient bases aims to improve the quality and improve the satisfaction of patients by monitoring the implemented procedures. Hospital employees, especially those who are in direct contact with patients, have the most significant impact on the assessment of the quality of hospital services, and consequently on patient satisfaction. According to the perception of the surveyed patients, the dimension of "reliability" (24.48\%) was the most desirable dimension of the quality of services, followed by "professionalism and confidence" (20.9\%). These two characteristics also express the high quality of medical services provided by a given hospital. In a study conducted in a private Iranian hospital, the dimension of "reliability" was recognized by the respondents, similarly to the present study, as the most significant in assessing the quality of medical services. The dimension related to empathy was for the Iranian patients in second place in terms of importance [11]. In contrast, the material dimension was the least important for the Iranian patients. In a study by Lewandowski, also conducted in a pediatric hospital, the most important dimension from the point of view of the patient was "readiness to meet the expectations of the patient", followed by the "material dimension" [12]. The team of Teamur Aghamolaei obtained survey results similar to Lewandowski. The most important dimension in the quality of medical services is also "readiness". However, the dimension related to empathy was classified in the last position [13]. Wolniak in his study demonstrates that the highest expectations of the patients occur in the case of variables belonging to the area of "readiness", while patients reveal the lowest expectations in terms of variables related to the area of empathy [14]. The area of "materiality" in the study of Domowicz was classified by patients as the least important, while higher significance was awarded to the variables of the "empathy" area. [15]. For the respondents in the present study the dimension of "materiality" was the least important, while for the subjects of Lewandowski this dimension held second position.

The reason for use in the present report of purposive group selection instead of a randomized trial is important from a methodological point of view. It should be noted that the study was conducted within the discipline of medicine, in which studies on the border of medical and economic science has not so far been conducted, and the quality of service was not clearly defined using these criteria. Another important limitation of the randomized study is access to the group of patients, as it results on one hand from the consent for conducting observation, and on the other hand from the consent granted by patients or their parents. In view of such limitations the study with purposive group selection seems optimum. The present study is of a pilot nature; however, no changes to this methodology are expected in the main study. The adopted criteria of the research sample selection and of subsequent reasoning may - according to the authors - be a basis for further interpretation, because of the comparability of the course of the disease, which undoubtedly constitutes a common element for patients being the subject of the study.

The results of the study of the quality of medical services demonstrated above are different from the present data. Most likely this difference is caused by the different culture and different expectations of the patients in relation to the health care services. However, all patients bear in mind their own welfare perceived from the angle of improving their health, and there are different "routes" which should lead to this effect. Furthermore, the present results demonstrated that the lowest expectations were associated with the material dimension and empathy. However, the expectations of the subjects are high in all dimensions of services. Moreover, the expectations of the patients were higher than their perception. The largest gap was demonstrated in the material dimension. Negative gaps indicate that the expectations of patients in the context of provided services are higher than their perception, so in the evaluation of the patients and the present study they have the least impact on the perception of life quality in terms of these dimensions.

The present study demonstrates that patients pay attention not only to clinical aspects related to the disease, but also to the surrounding areas, which have a direct impact on the perception of the quality of medical services provided to them. Therefore, not only the diagnosis made by physicians, but also many dimensions of life (like the abovementioned material dimension, reliability, readiness, professionalism and trust and empathy) influence the perception and assessment of the quality of life by the patient. The use of the SERVQUAL method allows for the identification of the characteristics of a medical service which are perceived as the most important by the hospitalized patient, as well as 
those which do not fully meet the expectations of patients. It should also be emphasized that it was not possible to find many publications on the application of the SERVQUAL method for the assessment of the quality of medical services in conservative hospitals in Polish scientific literature. Therefore, a preliminary hypothesis was made that the SERVQUAL model for quality measurement is a tool which allows for the measurement of the quality of services in hospitals in the subjective assessment of hospitalized patients.

The conducted study demonstrates results based on the assessment of the quality of medical services of one selected hospital ward. Furthermore, the surveyed number of patients was relatively small, which allowed only for a preliminary formulation of conclusions. Therefore, it is necessary to conduct the survey on a larger population of patients in a given hospital.

A holistic "approach" to the patient, and not only focusing on the clinical aspects of the disease should dominate. The present study also confirms the importance of the role of the medical and nursing staff taking care of patients during the hospitalization. Conversation, combined with elements of psychotherapy and strengthening positive incentives, favorably affects the assessment of the quality of provided medical services by the patient. The awareness of the gen- eral practitioner concerning the patient's satisfaction with hospital treatment and conditions of this treatment plays an important role for the area of confidence: physician-patient. The knowledge provided by the answers to survey questions contributes to the deinstitutionalization of patient care.

\section{Conclusions}

The results of the present study demonstrated that:

1. The SERVQUAL method helps to identify discrepancies between the perceptions of patients' expectations in all dimensions of the quality of provided medical services.

2. For the patients the least important is the material dimension, and the most affecting is the dimension associated with the reliability of the medical services.

3. Improvement of the level of satisfaction with the quality of medical services requires proper planning and effective actions while providing health care services.

4. It is recommended to conduct the study on a larger population of patients.

Source of funding: This work was funded by the authors' resources. Conflict of interest: The authors declare no conflict of interests.

\section{References}

1. Gętek M, Nowakowska-Zajdel E, Czech N, et al. Jakość życia pacjentów dializowanych i po przeszczepie nerek. Ann Acad Med Siles 2010; 64(5-6): 23-30.

2. Rutkowski B, ed. Leczenie nerkozastępcze w praktyce pielęgniarskiej. Gdańsk: Via Medica; 2008.

3. Sapilak BJ, Kurpas D, Steciwko A, et al. Czy jakość życia jest istotna dla chorych dializowanych? Na podstawie 3-letniej obserwacji pacjentów. Probl Lek 2006; 45(3): 89-93.

4. Ostrzyżek A. Jakość życia w chorobach przewlekłych. Probl Hig Epidemiol 2008; 89(4): 467-470.

5. Wojtaszek E, Matuszkiewicz-Rowińska J. Rola pielęgniarki w multidyscyplinarnym zespole terapeutycznym w leczeniu pacjentów z przewlekłą chorobą nerek. Nefrol Dial Pol 2008; 12(3): 44-46.

6. Grönroos C. Service management and marketing. New York: Maxwell Macmillan International; 1990.

7. Nekoei-Moghadam M, Amiresmaili MR. Hospital services quality assessment: Hospitals of Kerman University of Medical Sciences, as a tangible example of a developing country. Int J Health Care Qual Assur 2011; 24(1): 57-66.

8. Delene LM, Bunda MA, Kim C. Methods of measuring health-care service quality. J Bus Res 2000; 48(3): $233-246$.

9. Zeithaml VA, Bitner MJ. Service marketing. New York: Mc Graw Hill; 1996.

10. Brooks R, Linggs I, Botschen M. International marketing and customer driven wave fronts. Serv Ind J 1999; 19(4): 49-67.

11. Zarei A, Arab M, Rahimi FA, et. al. Service quality of private hospitals: the Iranian Patients' perspective. BMC Health Services Research 2012; 12: 31, doi: 10.1186/1472-6963-12-31.

12. Lewandowski R. Pomiar jakości usług medycznych z wykorzystaniem metody SERVQUAL. Probl Jakości 2008; 9(1): 30-35.

13. Aghamolaei T, Eghbal ET, Rafati S, et al. Service quality assessment of a referral hospital in Southern Iran with SERVQUAL technique: patients' perspective. BMC Health Services Research 2014; 14: 322, doi:10.1186/1472-6963-14-322.

14. Wolniak R. Pomiar oczekiwanej i postrzeganej jakości w usługach medycznych. Współcz Zarz 2010; 2(1): 135-137.

15. Domowicz B. Health care quality perception by hospital patients - a preliminary report. Hygeia Public Health 2013; 48(3): 352-354.

Address for correspondence:

Paweł Węgłowski, MSc

S7 Medical Company Sp. z o.o.

pl. Orląt Lwowskich $20 \mathrm{D}$

53-605 Wrocław

Polska

Tel.: +48 $690681-018$

E-mail: wupawel@gmail.com

Received: 24.05.2016

Revised: 27.06.2016

Accepted: 28.06.2016 